\title{
Classifiers in Japanese-to-English Machine Translation
}

\author{
Francis Bond and Kentaro Ogura and Satoru Ikehara \\ NTT Commmnication Science Laboratories \\ 1-2356 Take, Yokosuka-shi, Kanagawa-ken, JAPAN 238-03 \\ bond@nttkb.ntt.jp
}

\begin{abstract}
This paper proposes an analysis of classifiers into four major types: UNI'l,

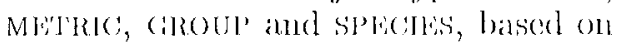
propertices of bolh Japanese and Eu. glish. The andysis makes possible at uniform and straight forward treatiment, of noun phrases hoaded by chassitions in Japanesco-bo- Jinglish machine translation, and has been implemented in the M'T system $\mathbf{\Lambda L T}-\mathbf{J} / \mathbf{E}$. Although the analysis is based on the characteristics of, and differences betwen, Japanesse and English, it is shown to be also ansplicable to the munclated langunge 'Jhai.
\end{abstract}

\section{Introduction}

Nomu phrases in Japanese difler from those in Hnglish in two important ways. Pirst, Japaneso has no equivalent syntaktic category to Finglish determiners. Seconcl, there is no grammatical marking of number.' Becautse of these differencess, numerical expressions are realized very differently in Japanese and English. In Whgtish, combtable nomes can be directly modilied by a mumeral: og dogs. In Japanese, however, numerals cannot di rectly modify common nouns, instead a chassifier is used, in the same way that a partitive noun is used with an uncountable noun in English: 2) pieces of furniture. In addition, when Japanese is translated into Fuglish, the solection of appropriate determiners, such as articles and possessive pronouns, and the determination of combatability and rumber is problematic.

Varions solutions to the problems of generating articles and possessive pronouns and determining comntability and number have been proposed (Murata and Nagao, 1993; Comish, Fujita, and Sugimura, 1994; Bond, Ogura, and Kawaoka, 1995). The differences between the way numerical expressions are realized in Japanese and binglish has beon less studied (Asahioka, Hirakawa, and Amano, 1990). Tn this paper we propose an analysis of elassifiers based on properties of both Japanese and English. (Our calegory of classifior inchucles both Japaneso josusht 'mumeral clas-

\footnotetext{
${ }^{1}$ Japanese does not have contrating singular and plumal forms of nouns.
}

sifiers' and English partitive nouns. We clivide classifiers into four major types: UNI'T, MHIRIe,

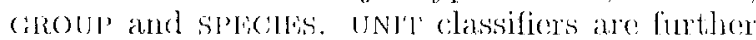
divided into cils

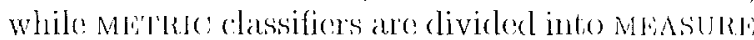
and con'lanele classifiers. Although our analysis was based on the characteristies of, and cliflerences betwen, Japanese and English, we fonnd it to he: strikingly similar to the analysis for 'J'hai proposed by Somlertlanvanich et al. (1994), which suggests that the results may be useful for examining other languages.

The analysis introduced in this paper has been implemented in N'I'T Conmunication Science laboratories' Japanesce-to-English machine tranlslation system ALI-J/E (lkohata ot al., 1991; (Ogura et al. 1993) simce 1994. Hxamples of how it has been intuplemented in $\mathbf{\Lambda} \mathbf{L} \mathbf{I}-\mathbf{J} / \mathbf{I}$; alle woven throughout the text, althongh the amalysis itsell is not, tied to any formalism or particular sepresentation, so is adaptable to any system

Wo start off by examining monolingual analyses of Japanese classifiers and Juglish partitive expressions (Section 2). Then we introduce om bilingual analysis of chassifiers and show how this malysis can bo used in a Japanese-to-Lnglish nat chine tamslation system (Section 3). Wo also examine nore complex cases where chassifiers ane nsed like normal notuss (Section 4). Finally wo compare on analysis to other people's (Section 5).

Throughout the paper wo use the following albreviations: $A, \mathrm{~B}$ or $\mathrm{N}$ : nom or noun phrase; $\mathrm{C}$ : classifier, $\mathrm{X}$ : Numeral, with Japanese in italies.

\section{Monolingual Analyses of Classifiers}

\subsection{Japanese 'Classifiers'}

Japaneso is a numeral classifior langlage (Allan, 1977 ), in which chassificrs are obligatory in many expressions of quantity. Wo will refer to prototypical Japanese classifiers as jostushi "numerical classiliers'.

Syntactically, josüshi are a subclass of nouns (Miyayki, Shirai, and Ikehare, 1995). Tho main property distinguishing them from nomal nomms is that they an postfix to mumerals, the culantifien su 'some' or the interrogative nane "what", to form a noun phrase. Unlike normal nouns in Japanese, 
josüshi can not form grammatical noun phrases on their own. ${ }^{2}$

(1) 2-hiki '2 animals'

(Numeral)

(2) su-hiki 'some animals'

(3) nan-hiki 'how many animals'

The resulting numeral-classifier noun phrase can modify another noun phrase, either linked by no 'of' ' $X C-n o-N$ ', or 'floating' elsewhere in the sentence, typically directly after the noun phrase it modifies ' $N X C$ '. It can also occur on its own, with anaphoric or deictic reference. Asahioka, Hirakawa, and Amano (1990) identify seven different patterns of use. In order to concentrate on the translation of classifiers and number, we will restrict our discussion to noun phrases of the type ' $X C-n o-N$ ' and not discuss the problems of resolving anaphoric reference and floating quantifiers.

Semantically, each classifier relates to a class of nouns (Kuno, 1973, 25), often fairly arbitrarily. For example -hiki '(small) animal' is used to count small animals excluding rabbits, which are counted with -wa 'bird'. There is a default classifier -tsu 'piece' which can be used to count almost anything.

\subsection{English 'Classifiers'}

In English, numerals can directly modify countable nouns ' $\mathrm{X} N$ '. In order to enumerate uncountable nouns, either the uncountable nouns have to be reclassified as countable nouns, or embedded in a partitive construction: two beers or two cans of beer ' $\mathrm{X} \mathrm{N}$ ' or 'X C of N' (Quirk et al., 1985, $249)$. This partitive construction is similar to the Japanese quantifying construction ' $X C-n o-N$ '.

Quirk et al. (1985, 249-51) divide partitive nouns into three main categories QUALITY PARTITIVES, QUANTITY PARTITIVES, and MEASURE PARTITIVES. QUANTITY PARTITIVES are further divided into three cases, the first where the embedded noun phrase is uncountable, the second where it is plural, and the third where it is singular and countable. All the partitive nouns themselves are fully countable.

QUANTITY PARTITIVES where the embedded noun phrase is headed by an uncountable noun, the first case, are then divided into GENERAL PARTITIVES such as piece which serve only to quantify and TYPICAL PARTITIVES such as grain which are more descriptive.

\footnotetext{
${ }^{2}$ There are some examples of words that can be either a common noun or josīshi: for example gyō 'line' or hako 'box', which can follow a numeral or stand alone. These nouns can be handled in two ways: (a) as a lexical class that combines the properties of common nouns and josüshi, or (b) as two separate lexical entities. ALT-J/E follows option (b), such nouns are entered into the lexicon twice, once as a common noun and once as a josiushi.
}

\section{A Bilingual Analysis of classifiers}

As there is no direct fit between English and Japanese, it is necessary to categorize the Japanese and English classifiers and to define rules which will enable effective machine translation. We divide classifiers into four major types: UNI'T (Section 3.1), METRIC (Section 3.2), GROUP (Section 3.3) and SPECIES (Section 3.4). The main criteria for the analysis are the restrictions placed, in English, on the countability and number of the embedded noun phrase in a partitive construction. Whether a noun is a classifier, and if so which type, is marked in the lexicon for each Japanese/English noun pair.

We distinguish between five major different noun countability preferences, based on the analysis of Allan (1980), adapted for use in machine. translation by Bond, Ogura, and Ikehara (1994). 'Fully countable' nouns, such as knife, have both singular and plural forms, and cannot be used with determiners such as much. 'Uncountable' nouns, such as furniture, have no plural form, and can be used with much. Between these two extremes are nouns such as cake, which can be used in both countable and uncountable noun phrases. They have both singular and plural forms, and can also be used with much. We divide such nouns into two groups: 'strongly countable', those that are more often used to refer to discrete entities, such as cake, and 'weakly countable', those that are more often used to refer to unbounded referents, such as beer. The fifth major type of countability preference is 'pluralia tanta': nouns that only have a plural form, such as scissors.

\subsection{Unit classifiers}

UNIT classifiers are the prototypical classifiers. A UNIT classifier will be realized in Japanese as a josushi. However, there are three possible translations of a Japanese noun phrase of the form ' $\mathrm{XC}$ $n o-N$, where $C$ is a unit classifier:

Individuate: Translate as ' $\mathrm{X} N$ ', where the classifier $C$ is not translated and the numeral directly modifies the countable English noun phrase:

1-hiki-no-inu '1-piece of $\mathrm{dog}^{\prime} \rightarrow 1 \mathrm{dog}$.

Part: Translate as ' $\mathrm{X} \mathrm{C}$ of N', where the classifier is translated by its translation equivalent (from the transfer dictionary) and $\mathrm{N}$ is uncountable (headed by a bare singular noun): 1-tsubu-no-kome '1-grain of rice' $\rightarrow 1$ grain of rice.

Default: Translate as ' $\mathrm{X}$ C of N' where the classifier is replaced by a default that depends on the embedded noun and $\mathrm{N}$ is uncountable. The default is normally piece, but this can be over-ridden by an explicit entry for N's default classifier in the lexicon: 
Table 1: Unit Classifiers

\begin{tabular}{|l|l|l|l|}
\hline Noun Type & General & Special \\
\hline Fully Countable & 1 dog & 1 dog & 1 slice of dog \\
Strongly Countable & 1 cake & 1 crumb of cake & 1 slice of cake \\
Weakly Countable & 1 hair & 1 strand of hair & 1 slice of hair \\
Uncountable & 1 piece of information & 1 grain of information & 1 slice of information \\
Pluralia Tanta (pair) & 1 pair of scissors & 1 pair of scissors & - \\
\hline
\end{tabular}

1-tsu-no-kagu '1-piece of furniture' $\rightarrow 1$ piece of furniture.

The three types of UNIT classifier are summarized in Table $1 .{ }^{3}$

Having established three possible translations of the ' $X C-n o-N$ ' construction, we can proceed to divide UNIT classifiers into three types, depending on which of the above alternatives is most suitable. The first, GENeres classifiers, are those that have no special meaning of their own, but are used only to quantify the denotation of a noun. Typical examples are - tsu 'piece' and -ko 'piece'. If $\mathrm{N}$ is fully, strongly or weakly countable, then the classifier is not translated (individuate). If $\mathrm{N}$ is uncountable, then the classifier is translated as the default (default). The second type of classifier, TYPICAL, consists of those classifiers which are descriptive in their own right, such as -teki 'drop'. If $\mathrm{N}$ is fully countable, then the classificr will not be translated (individuate), otherwise the classifier is translated (part). The final type of classifier, SpECInI, is rare: classifiers which force an uncountable interpretation of even countable nouns, for example-kire 'slice'. $\mathrm{N}$ is always parted: 1 -kireno-inu ' 1 -slice of dog' $\rightarrow 1$ slice of dog.

The translation of classifiers is complicated by the fact that classifiers and their relationships to nouns are both arbitrary and language dependent. Consider the Japanese classifier -mai 'sheet', which is used for counting flat objects. This has no direct English equivalent. As a default, it is entered in the dictionary as a GENERAI. classifier with the translation piece. There are however scveral flat objects for which piece is inappropriate in English: food-stuffs (slice); paper, glass, cloth and leather (sheet); bacon (rasher); and financial contracts (contract). The selection of an appropriate translation is not dependent on this analysis and can be left to the normal machine translation process. In ALT-J/E it is done by examining the semantic category of the cmbed-

\footnotetext{
${ }^{3}$ If N's countability preference is pluralia tanta then $\mathrm{N}$ will never be individuated. If $\mathrm{N}$ is parted or defaulted there are two possibilities: either, if the dictionary entry for $\mathrm{N}$ has the default classifier pair then it will be used as the classifier or, if $\mathrm{N}$ has no default classifier, then a different translation is searched for in the dictionary and used instead. If there is no nonpluralia tanta translation equivalent, then the translation will default to ' $\mathrm{X} \mathrm{C}$ of $\mathrm{N}$ ' as above, but with $\mathrm{N}$ headed by a bare plural noun.
}

ded noun. Once an appropriate translation of the classifier has been found, knowledge of its type allows the system to decide the appropriate form of the final translation.

\subsection{Metric classifiers}

The next overall category is METRIC classifiers $\Lambda$ noun phrase of the form ' $X C-n o-N$ ', where $\mathrm{C}$ is a METRIC classifier will be translated as ' $\mathrm{X} \mathrm{C}$ of $\mathrm{N}$, where $\mathrm{N}$ will be plural if it is headed by a fully countable or pluralia tanta noun. We further subdivide METRIC classifiers depending on whether the resulting English noun phrase will have singular verb agreement (MLASURL classifiers), or plural verb agreement (CONTAINER classifiers) as its default.

(4) 2-kg-no-kami-ha jübun da '2 kg of paperTOr' enough is' $\rightarrow 2 \mathrm{~kg}$ of paper is enough

(5) 2-hako-no-kami-ha jübun da '2 box of paper-Tor enough is' $\rightarrow 2$ boxes of paper are enough

In fact both (4) and (5) could be translated with singular or plural verb agreement. The differentiation into MEASURE and CONTAINER provides a graceful default. Examples are given in Table 2.

\subsection{Group classifiers}

GROUP classifiers combine with plural or uncountable noun phrases to make a countable noun phrase representing a group or set. A noun phrase of the form ' $X C-n o-N$ ', where $\mathrm{C}$ is a GRoup classifier will be translated as ' $\mathrm{X} \mathrm{C}$ of $\mathrm{N}$ ', where $\mathrm{N}$ will be plural if it is headed by a fully or strongly countable noun or a pluralia tanta. Noun phrases of the form ' $N$-no- $C$ ', where $\mathrm{C}$ is a GRoup classifier (but not a josüshi) will also be translated as ' $\mathrm{C}$ of $\mathrm{N}$ ' where $\mathrm{N}$ will be plural if it is headed by a fully or strongly countable noun or a pluralia tanta. This allows us to give a uniform treatment of noun phrases such as (6) and (7) during English generation, even though their Japanese structure is very different.

(6) 2-hako-no-pen '2 box of pen' $\rightarrow 2$ boxes of pens ' $X C-n o-N$ '

(7) pen-no-hako 'box of pen' $\rightarrow$ a box of pens

$' N-n o-C '$ 
Table 2: Container and Moasure Classificrs

\begin{tabular}{|l|l|l|}
\hline Noun Type & Container & Measure \\
\hline Fully Countable & 1 box of dogs & $1 \mathrm{~kg}$ of ants \\
Strongly Countable & $1 \mathrm{box}$ of cake & $1 \mathrm{~kg}$ of cake \\
Weakly Countable & $1 \mathrm{box}$ of becr & $1 \mathrm{~kg}$ of becr \\
Uncountable & $1 \mathrm{box}$ of furniture & $1 \mathrm{~kg}$ of furniture \\
Pluralia Tanta & 1 box of scissors & $1 \mathrm{~kg}$ of scissors \\
\hline
\end{tabular}

Table 3: Group and Species Classifiers

\begin{tabular}{|l|l|l|l|}
\hline Noun Type & Group & Species (Si) & Species (1) \\
\hline Fully Countable & 1. set of dogs & 1 kind of dog & 2 kinds of dogs \\
Strongly Countable & 1 set of cakes & 1 kind of cake & 2 kinds of cakes \\
Weakly Countable & 1 set of ber & 1 kind of beer & 2 kinds of beer \\
Uncountable & 1. set of information & 1. kind of information & 2 kinds of information \\
Pluralia Tantad & 1 set of scissors & 1 kind of scissors & 2 kinds of scissors \\
\hline
\end{tabular}

Whether a noun is a ciloup classifier or not can also be used to help determine the number of ascriptive and appositive noun phrases. For example, in ALT-J/E the countability and number of two appositive noun phrases are made to match each other, unless one element is plural and the other is a Group classifier. For example, many insects, a whole swarm, ... as opposed to many insects, bees I think, ... (Bond, Ogura, and Kawaoka, 1995). Examples of Groul classificrs are given in Table 3 .

\subsection{Species classifiers}

The last type of classifier is splicies classifiers. specirs classifiers are partitives of quality and can occur with countable or uncountable noun phrases. The embedded noun phrase will agreo in number with the head noun phrase if fully or strongly countiable: a kind of car, 2 kinds of cars; a kind of equipment, 22 kinds of equipment. Examples of spectes classifiers are given in Table 3.

\section{When is a Classifier a Classifier?}

In the analysis given above for Japanese noun phrases of the form ' $X C-n o-N$ ', wo have given no consideration to the denotation of $\mathrm{N}$, except for when choosing the appropriate translation for $\mathrm{C}$. Thus we assume that ' $X C-n o-N$ ' will be translated as ' $\mathrm{X}$ C of $\mathrm{N}$ ' or just ' $\mathrm{X} \mathrm{N}$ ' if $\mathrm{N}$ is countiable, as in $(8)$ or $(9)$.

(8) 1-pai-no mizu '1-cup of water' $\rightarrow 1$ cup of water (CONTAINER)

(9) 1-tsu-no koppu '1-piece of cup' $\rightarrow 1$ cup (GENIRAI)

However if $\mathrm{N}$ is a noun that denotes an attribute, such as PRICE or Wrigil', then the translation process becomes more complicated. In the simplest, case the noun phrase ' $X C-n o-N$ ' should be translated as though the classifier were a normal noun, giving 'the $\mathrm{N}$ of X C', for example (10), (11).
(10) 1-pai-no nedan ' 1 -cup) of price'

$\rightarrow$ the price of 1 cup

(11) 1-tsu-no nedan [-ha 10en da] '1-pices of price [-TOP 10 yen is]'

$\rightarrow$ the price of 1 (thing) [is 10 yen]

In other words, if $\mathrm{N}$ has the attribute $\Lambda \mathrm{MOUN}$ I then the noun phrase should normally be translated as though $\mathrm{C}$ wore not a classifier. The interpretation of $\mathrm{C}$ is, however, ambiguous. C could be used as a classifier with the amount $\mathrm{N}$ in its scope (12), or $\mathrm{C}$ could have anaphoric reference (13). AIT-J/E chooses the interpretation shown in example (13) as its default.

$$
\begin{aligned}
& \text { (12) } 1 \text {-shü-no nedan ' } 1 \text { kind of price' } \\
& \rightarrow 1 \text { kind of price. } \\
& \text { (13) } 1 \text {-shui-no nedan ' } 1 \text { kind of price' } \\
& \rightarrow \text { the price of } 1 \text { kind [of something] }
\end{aligned}
$$

Further, when $\mathrm{N}$ is an attribute and $\mathrm{C}$ measures the same attribute, the interpretation is again different. For example, if C measures N's attribute then the resulting noun phrase will bo indefinite by default: a height of $10 \mathrm{~m}$ or a price of 10 yen. However if the noun phrase is used ascriptively then it should be converted either to an adjective it is $10 \mathrm{~m}$ high or a prepositional phrase it is 10 yen in price. Finally, if a noun phrase of this type: is used to modify another noun then it needs to be converted to an adjective a $10 \mathrm{~m}$ high building or a post modifying prepositional phrase a chocolate 10 yen in price.

The combinations of nouns and classificers mentioned above can all be translated by the inachine translation system ALT-J/E using the analysis of classifiers presented in this paper in combination with a semantic hicrarchy of 2,800 categories common to all nouns, as described in Ikchara et al. (1991). The particle no 'of', has many possible interpretations, Shimazu, Naito, and Nomura (1987) identify dive main types of $A-n o-B$ exprossions, and some 80 
Table 4: Proposed Analysis of Clatsifiers

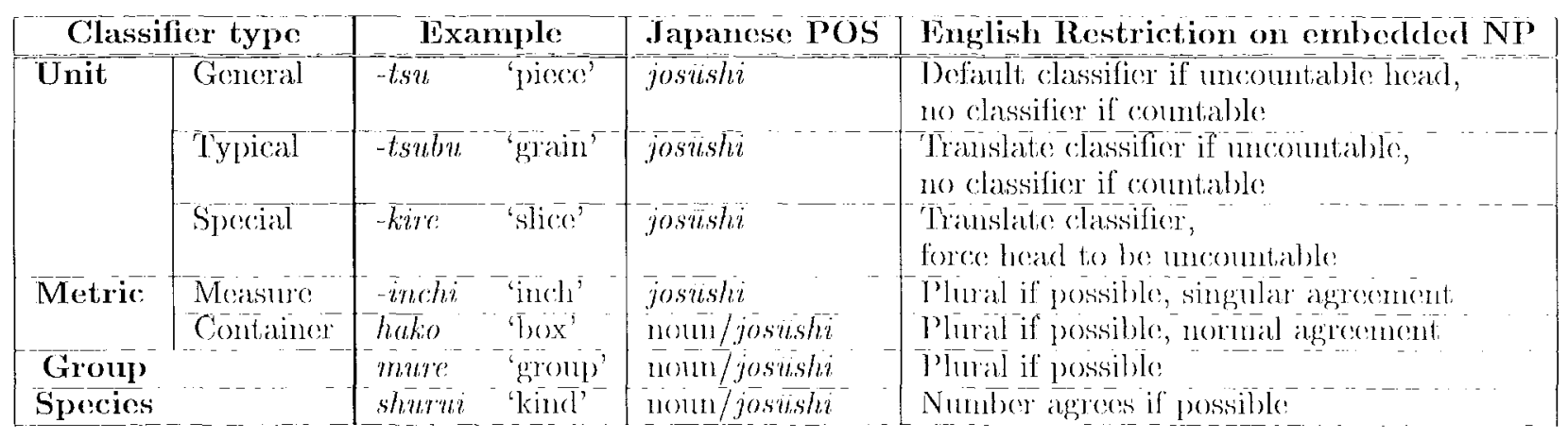

Table 5: A comparison of different analyses

\begin{tabular}{|c|c|c|c|c|}
\hline \multicolumn{2}{|c|}{ Proposed Analysis } & Quirk et al. & Kamei et al. & Sornlertlamvanich et al. \\
\hline \multirow[t]{2}{*}{ Unit } & General & Quantity-General & \multirow[b]{2}{*}{ l'iece: } & \multirow[b]{2}{*}{ Unit } \\
\hline & $\begin{array}{l}\text { Typical } \\
\text { Special }\end{array}$ & Quantity-Typical & & \\
\hline \multirow[t]{2}{*}{ Metric: } & Measture & Moastile & Unit. & \multirow{2}{*}{ Metric: } \\
\hline & Contiainor & & Contaner & \\
\hline \multicolumn{2}{|l|}{ Groulp } & Quimitity-1 Tuaral & $\sin -2$ & Collective \\
\hline \multicolumn{2}{|l|}{ Species } & Quality & Kind - - & \\
\hline \multicolumn{2}{|l|}{ (Unit) } & $\ldots-\ldots-\ldots$ & Times & lropluency \\
\hline \multicolumn{2}{|l|}{ (Unit) } & & & Verbal \\
\hline
\end{tabular}

sub types. On analysis cuts across Shimazn of al.'s types, including at least three of the subtypes, and also makes clear some relations that are not explicitly named.

\section{Comparisons with other Analyses}

Wo summarian our analysis of classifiers in 'Thble 4. Our analysis was based mainly on the properties of the generated finglish, so is naturally quite close to the division of partitive nouns proposed by Quirk of al. (1985). The analysis is also quite close to those proposed by Kamei and Muraki (1995) for Japanese and Sornlertlamvanich of al. (1994) for 'Thai. 'This supports Allan's (1977) assertion that "diverse language communities categorize perceived phenomena in similar ways". The different analyses are compared in Table: 5.

Wo make the distinction between classifiers of frequency and other Unt' classifiers by using our general semantic hiorarchy. Sormlertiamvanich et al.'s VBrRAs chassifiers "any classifien which is derived from a verb $[.$.$] / kraad hat$ muan/ "five rolls of paper'." can be included in the Mrirke category, although it may be the case that they have a different part of specech in 'Thai. Kamei and Muraki (1995) put UnI'I' classifiors into two classes: 'Counting Total Amonnt,' $3 k g$ of sugar and 'Counting an Nttrilunte Value': a speed of $60 \mathrm{mph}$. This distinction belongs to the interpretation of the classifior in context, rather than its inherent properties, so we feel the distinction should be made during processing, as described in Section 4, rathen than as part of the analysis of the classifiens themselvess.

\section{Conclusion}

In this paper we present an analysis of classifiers, suitable for use in a Japanese-to-English maxhine: translation system. We divide classifiers into fou

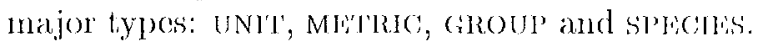
UNI'T classifiers are further divided into (iINISRAI,

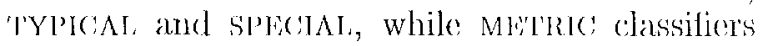

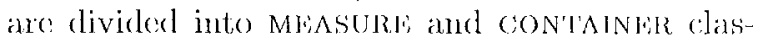
sifiors. The analysis is based on chameteristics peculiar to Japanese and Finglish, as woll as the differences between them. The rosulting analysis is shown to bo similar to one proposed for Thai, an unrelated language, suggesting lihat, it may be more wirlely applicable.

'The analysis has been implemented in N'I'T"s Japanese-to-English machine translation system AIT-J/L since 1994. It makes possible a miform and straightforward treatment of nom phrases headed by classifiers.

Further work remains to be done in exmming the distribution of classifiers in different domains, and possibly identifying classifiers antomatically. 


\section{References}

Allan, Keith. 1977. Classifiers. Language, 53:285311.

Allan, Keith. 1980. Nouns and countability. Language, 56(3):541-67.

Asahioka, Yoshimi, Hideki Hirakawa, and Shin-ya Amano. 1990. Semantic classification and an analyzing system of Japanese numerical expressions. IPSJ SIG Notes 90-NL-78, 90(64):129-136, July. (in Japanese).

Bond, Francis, Kentaro Ogura, and Satoru Ikehara. 1994. Countability and number in Japanese-toEnglish machine translation. In Proceedings of the 15th International Conference on Computational Linguistics (COLING '94), pages 32-38, August. (cmp-lg/9511001).

Bond, Francis, Kentaro Ogura, and Tsukasa Kawaoka. 1995. Noun phrase reference in Japanese-to-English machine translation. In Proceedings of the Sixth International Conference on Theoretical and Methodological Issues in Machine Translation (TMI '95), pages 1-14, July. (cmp-lg/9601008).

Cornish, Tim, Kimikazu Fujita, and Ryochi Sugimura. 1994. Towards machine translation using contextual information. In Proceedings of the 15th International Conference on Computational Linguistics (COLING '94), pages 51-56, August.

Ikehara, Satoru, Satoshi Shirai, Akio Yokoo, and Hiromi Nakaiwa. 1991. Toward an MT system without pre-editing - effects of new methods in ALT$\mathbf{J} / \mathbf{E}-$. In Proceedings of MT Summit III, pages 101-106. (cmp-lg/9510008).

Kamei, Shin-ichiro and Kazunori Muraki. 1995. An analysis of NP-like quantifiers in Japanese. In Proceedings of the Natural Language Processing Pacific Rim Symposium (NLPRS '95), volume 1, pages 163-167.

Kuno, Susumu. 1973. The Structure of the Japanese Language. MIT Press, Cambridge, Massachusetts, and London, England.

Miyazaki, Masahiro, Satoshi Shirai, and Satoru Ikehara. 1995. A Japanese syntactic category system based on the constructive process theory and its use. Journal of Natural Language Processing, 2(3):3-25, July. (in Japanese).

Murata, Masaki and Makoto Nagao. 1993. Determination of referential property and number of nouns in Japanese sentences for machine translation into English. In Proceedings of the Fifth International Conference on Theoretical and Methodological Issues in Machine Translation (TMI'93), pages 21825, July.

Ogura, Kentaro, Akio Yokoo, Satoshi Shirai, and Satoru Ikehara. 1993. Japanese to English machine translation and dictionaries. In Proceedings of the 44th Congress of the International Astronautical Federation, Graz, Austria.

Quirk, Randolph, Sidney Greenbaum, Geoffrey Leech, and Jan Svartvik. 1985. A Comprehensive Grammar of the English Language. Longman, Essex.
Shimazu, Akira, Shozo Naito, and Hirosato Nomura. 1987. Semantic structure analysis of Japanese noun phrases with adnominal particles. In Proceedings of the 25th Annual Meeting of the ACL, pages 123130. Association for Computational Linguistics.

Sornlertlamvanich, Virach, Wantanee Pantachat, and Surapant Meknavin. 1994. Classifier assignment by corpus-based approach. In Proceedings of the 15th International Conference on Computational Linguistics (COLING '94), pages 556-561, August. 